\title{
Human colonic crypts in culture: segregation of immunochemical markers in normal versus adenoma-derived
}

\author{
Michael K Dame ${ }^{1,5}$, Yan Jiang ${ }^{2,5}$, Henry D Appelman ${ }^{1}$, Kelly D Copley ${ }^{1}$, Shannon D McClintock ${ }^{1}$, \\ Muhammad Nadeem Aslam ${ }^{1}$, Durga Attili ${ }^{1}$, B Joseph Elmunzer ${ }^{3}$, Dean E Brenner ${ }^{2,4}$, James Varani ${ }^{1,6}$ and \\ D Kim Turgeon ${ }^{3,6}$
}

In order to advance a culture model of human colonic neoplasia, we developed methods for the isolation and in vitro maintenance of intact colonic crypts from normal human colon tissue and adenomas. Crypts were maintained in threedimensional Matrigel culture with a simple, serum-free, low $\mathrm{Ca}^{2+}(0.15 \mathrm{mM})$ medium. Intact colonic crypts from normal human mucosa were viably maintained for 3-5 days with preservation of the in situ crypt-like architecture, presenting a distinct base and apex. Abnormal structures from adenoma tissue could be maintained through multiple passages (up to months), with expanding buds/tubules. Immunohistochemical markers for intestinal stem cells (Lgr5), growth (Ki67), differentiation (E-cadherin, cytokeratin 20 (CK20) and mucin 2 (MUC2)) and epithelial turnover (Bax, cleaved Caspase-3), paralleled the changes in function. The epithelial cells in normal crypts followed the physiological sequence of progression from proliferation to differentiation to dissolution in a spatially and temporally appropriate manner. Lgr5 expression was seen in a few basal cells of freshly isolated crypts, but was not detected after 1-3 days in culture. After $24 \mathrm{~h}$ in culture, crypts from normal colonic tissue continued to show strong Ki67 and MUC2 expression at the crypt base, with a gradual decrease over time such that by days 3-4 Ki67 was not expressed. The differentiation marker CK20 increased over the same period, eventually becoming intense throughout the whole crypt. In adenoma-derived structures, expression of markers for all stages of progression persisted for the entire time in culture. Lgr5 showed expression in a few select cells after months in culture. Ki67 and MUC2 were largely associated with the proliferative budding regions while CK20 was localized to the parent structure. This ex vivo culture model of normal and adenomatous crypts provides a readily accessible tool to help understand the growth and differentiation process in human colonic epithelium.

Laboratory Investigation (2014) 94, 222-234; doi:10.1038/labinvest.2013.145; published online 23 December 2013

KEYWORDS: adenoma; apoptosis; chemoprevention; colon crypt culture; cytokeratin 20; Lgr5; mucin 2

Epithelial cells in the normal human colonic crypt progress through stages of proliferation and differentiation in a temporally and spatially distinct manner. Stem cells at the crypt base give rise to rapidly dividing transit-amplifying cells that move upward, ${ }^{1}$ differentiating into lineage progeny of absorptive enterocytes, mucin-secreting goblet cells and endocrine cells. As the cells reach the apex they terminally differentiate and are sloughed into the lumen. Turnover of the colonic mucosa occurs in 3-5 days, ${ }^{2}$ short compared with other epithelial tissues.
Carcinogenesis in the colonic mucosa is a complex, multistep process. Genetic anomalies occur in the epithelial cells long before there is a visible change in the mucosal structure. These genetic changes alter the normal cellular response to factors that regulate growth and differentiation. ${ }^{3}$ The first cytological and histological evidence of abnormal growth are areas of epithelial cell hyperproliferation, which give rise to aberrant crypts. ${ }^{4}$ The aberrant crypts often have increased length, and some of the cells within these crypts have lost

\footnotetext{
${ }^{1}$ Department of Pathology, University of Michigan, Ann Arbor, MI, USA; ${ }^{2}$ Department of Internal Medicine, Comprehensive Cancer Center, University of Michigan, Ann Arbor, MI, USA; ${ }^{3}$ Division of Gastroenterology, Department of Internal Medicine, University of Michigan, Ann Arbor, MI, USA and ${ }^{4}$ Medical Service and Geriatrics Research Education and Clinical Center, VA Medical Center, Ann Arbor, MI, USA

Correspondence: MK Dame, BS, Department of Pathology, University of Michigan Medical School, 1301 Catherine Street, Ann Arbor, MI 48109-5602, USA.

E-mail:mdame@med.umich.edu

${ }^{5}$ These authors contributed equally to this work.

'Laboratories of DK Turgeon and J Varani contributed equally to this work.

Received 9 August 2013; revised 4 November 2013; accepted 11 November 2013
} 
their ordered pattern of differentiation as seen in normal crypts. These hyperplastic areas may further develop into adenomas with overt cytological and histological abnormalities. Over years, additional changes in a fraction of the cells comprising the adenomas may lead to invasive adenocarcinoma. ${ }^{5}$

Much of our current understanding of the development of colonic cancer comes from experiments in animal models ${ }^{6}$ or from studies using human colon cancer-derived cell lines. ${ }^{7}$ Most studies conducted with fresh human colon tissue have been limited to ex vivo analytical assessments to characterize cellular and molecular profiles of premalignant/malignant tissue. ${ }^{8,9}$ Procedures for maintaining human colonic tissue in organ cultures have been described. ${ }^{10-12}$ The utility of colon organ culture has not been established. Important limitations include the relatively small number of unit-cultures that can be prepared from a typical colonic resection, the wide variability in the unit-cultures (eg, size, percent stroma), the rapid dissolution of the mucosa in culture and the difficulty of interrogating/analyzing changes in the tissue.

Whitehead et all isolated individual crypts from human colon mucosa and cultured the crypt-derived epithelial cells in a three-dimensional (3-D) collagen gel. Others have used his isolation methods: to establish short-term cultures of primary epithelial cells from crypts; ${ }^{14,15}$ to initiate $3-\mathrm{D}$ enteroid/organoid cultures derived from colonic stem cells; ${ }^{16,17}$ and to examine time-zero ex vivo crypts. ${ }^{18,19}$ Work in the organoid model has demonstrated the capacity to recapitulate the colon epithelial cell lineage profile. ${ }^{17}$ Monolayer cultures and organoid cultures both provide opportunity for interventional studies as well as analytical studies, however, the architecture of the intact crypt is lost or modified-defining features that maintain normal tissue physiology/pathophysiology and distinguish normal from the premalignant/malignant phenotypes. The maintenance of the histologically intact crypt structure in culture has had limited outcome (up to $16 \mathrm{~h}$ survival). ${ }^{20}$

In regard to the culture of human adenoma, one study reported that microadenoma was sustained in a 3-D alginate gel support for months, although without expansion of the starting material. ${ }^{21}$ Recently, murine-derived adenoma has been expanded in culture. ${ }^{17}$ This study describes the isolation and maintenance of intact colonic crypts from normal human colon tissue; and the isolation and in vitro expansion of human colonic adenomas.

\section{MATERIALS AND METHODS}

\section{Isolation and 3-D Culture of Colonic Crypts}

Tissue procurement

Normal colon tissue was procured from 15 resections at the University of Michigan Hospitals (Table 1). The tissue was de-identified and deemed by the Institutional Review Board to be exempt from IRB oversight. Normal tissue is defined as being at least $10 \mathrm{~cm}$ from the disease margin and having a histologically normal appearance. Human adenoma tissue was procured as biopsies taken in situ from six large adenomas $(>1 \mathrm{~cm})$, preceding endoscopic resection (Table 2). Each case provided $1-3$ biopsies, about $5 \mathrm{mg}$ in size.

Tissues were transported to the laboratory in cold Dulbecco's minimal essential medium (Life Technologies, Carlsbad, CA, USA), supplemented with $2 \mathrm{mM}$ GlutaMax (Life Technologies), $50 \mu \mathrm{g} / \mathrm{ml}$ gentamicin (Life Technologies), $100 \mu \mathrm{g} / \mathrm{ml}$ normocin (InvivoGen, San Diego, CA, USA) and $2.5 \mu \mathrm{g} / \mathrm{ml}$ amphotericin (Life Technologies). The period of time for tissue transport, from surgical removal to the initiation of the isolation procedure, was: $25-75 \mathrm{~min}$ for normal resected colon tissue and 10-20 min for biopsied adenomas.

Table 1 Histologically normal colonic tissue information

\begin{tabular}{|c|c|c|c|c|}
\hline Gender & Age & Associated diagnosis & $\mathrm{Mg}^{\mathrm{a}}$ & \# Crypts \\
\hline Female & 63 & Adenocarcinoma & 1116 & 15800 \\
\hline Male & 46 & Adenocarcinoma & 660 & 8400 \\
\hline Male & 37 & Adenocarcinoma & ND & ND \\
\hline Male & 45 & Adenocarcinoma & ND & ND \\
\hline Female & 60 & Adenocarcinoma & 478 & 6100 \\
\hline Male & 72 & Adenocarcinoma & 672 & 3400 \\
\hline Female & 53 & Adenoma & ND & ND \\
\hline Male & 61 & Adenoma & 857 & 15000 \\
\hline Female & 62 & Adenoma & ND & ND \\
\hline Male & 67 & Adenoma & 1714 & 16200 \\
\hline Female & 50 & Adenoma & 500 & 13500 \\
\hline Male & 72 & Adenoma & 855 & 13200 \\
\hline Male & 64 & Adenoma & 1024 & 4400 \\
\hline Female & 21 & Colonic inertia & ND & ND \\
\hline Female & 41 & Sarcoma & ND & ND \\
\hline
\end{tabular}

Histologically normal tissue is defined as at least $10 \mathrm{~cm}$ from the margin of diseased tissue.

${ }^{\mathrm{a} D i s s e c t e d ~ m u c o s a l ~ t i s s u e ~ w e i g h t ~(N D, ~ v a l u e s ~ n o t ~ d e t e r m i n e d) . ~}$

Table 2 Adenoma tissue and culture information

\begin{tabular}{lcc}
\hline Gender & Age & Culture time (days) \\
\hline Female & 18 & $186+$ \\
Male & 51 & $88+$ \\
Female & 69 & $81+$ \\
Female & 67 & 21 (ended) \\
Male & 70 & $15+$ \\
Male & 53 & 14 (contaminated)
\end{tabular}

Cultures initiated from structures isolated from 1 to $35 \mathrm{mg}$-biopsies per donor. All cases were large adenoma $(>1 \mathrm{~cm})$, with no evidence of familial adenomatous polyposis. 


\section{Tissue preparation and non-enzymatic digestion}

The isolation of normal human colonic crypts was adapted from both recent ${ }^{16}$ and previous work. ${ }^{13,14}$ Isolation from adenoma biopsies was essentially the same as that done with normal tissue, with the exception of the final separation from lamina propria (outlined below). For normal tissue, the mucosa/submucosa was first surgically separated from the muscularis propria (see diagrammatic in Dame and Varani $^{22}$ ). The tissues (normal mucosa or intact adenoma biopsy) were incubated in room temperature Dulbecco's phosphate-buffered saline (DPBS; Life Technologies), supplemented with the above antimicrobials for $15 \mathrm{~min}$. The tissues were weighed and cut into $2-3 \mathrm{~mm}$ pieces and incubated at room temperature in fresh $10 \mathrm{mM}$ dithiothreitol (DTT; Sigma-Aldrich, St Louis, MO, USA) for $15 \mathrm{~min}$, refreshing DTT every $5 \mathrm{~min}$. The tissues were then rinsed twice with DPBS supplemented with gentamicin and normocin. The tissues were rinsed once with cold $8 \mathrm{mM}$ ethylenediaminetetraacetic acid (EDTA; Sigma-Aldrich) and then rotated gently for $75 \mathrm{~min}$ in cold EDTA. The EDTA was carefully removed and the tissue pieces were washed three times with cold DPBS (with gentamicin and normocin), settling between each wash.

\section{Crypt separation from lamina propria-normal tissue}

The normal crypts were agitated free from the surrounding lamina propria in three subsequent shaking periods. For each period, new DPBS (with gentamicin and normocin) was added to the settled tissue, which was then shaken manually 10 times and added to $500 \mu \mathrm{l}$ cold fetal bovine serum (characterized FBS; Thermo Scientific Hyclone, Pittsburgh, PA, USA). All subsequent washes and growth media were phenol red-free, antimicrobial-free and supplemented to a final concentration of $0.15 \mathrm{mM}$ calcium chloride. The crypts were washed two times with cold Keratinocyte Basal Medium Gold (Lonza, Walkersville, MD, USA), containing 5\% FBS, and pelleted with slow centrifugations $\left(2 \mathrm{~min} ; 40 \times g ; 4{ }^{\circ} \mathrm{C}\right)$. A final wash was done with cold keratinocyte growth medium gold (KGMG), which includes human epidermal growth factor, recombinant human insulin, human transferrin, hydrocortisone, epinephrine and bovine pituitary extract. Before the third wash, three $50 \mu$ l samples were taken to estimate crypt number. Immediately following the third wash, Matrigel (354234; BD Biosciences, San Jose, CA, USA) was added to the pellet and aliquotted at a crypt density of 50-75 crypts $/ 50 \mu$ l Matrigel $/ 2 \mathrm{~cm}^{2}$ well (Nunc LabTek II 4-Well Chamber Slide System; Thermo Scientific). Cultures were placed in a humidified tissue culture incubator at $37^{\circ} \mathrm{C}$ and $5 \% \mathrm{CO}_{2}$ in $95 \%$ air. After 30 min, $500 \mu \mathrm{l} \mathrm{KGMG} \mathrm{per} \mathrm{well} \mathrm{was}$ added. At $3 \mathrm{~h}$, the media was replaced to remove non-viable cellular products (Grossmann et al ${ }^{14}$ found that a 3-h media change was important to remove unattached crypts for his colon epithelial cell explant cultures). Subsequently, media was changed every $24 \mathrm{~h}$. A critical aspect of successful colon crypt culture was the importance of reducing the accumulation of culture detritus at the initiation of and over time in culture (ie, products of dead/dying cells due to anoikis of disaggregated epithelia and normal end-stage epithelial differentiation and death, residual mucus, etc.). This was addressed (1) by seeding with a low number of crypts and (2) by frequent media changes. This held true for the adenoma cultures as well.

\section{Crypt separation from lamina propria-adenoma tissue}

The twisting and budding nature of the abnormal epithelial structure does not allow for smooth detachment from its surrounding stromal tissue. The abnormal crypt structures remained loosely associated with their supporting tissue, after the DTT/EDTA incubation periods. In addition, frequently the pieces were buoyant and adhesive, possibly due to associated mucin. For this reason, after the incubation periods in DTT/EDTA, structures were manipulated and washed in a Petri dish on ice. The pieces were minced in cold matrigel with a scalpel. Remaining pieces (approximately $1 \mathrm{~mm}^{2}$ ) were removed with a forceps and discarded. Adenoma fragments that were just small enough $(50-250 \mu \mathrm{m})$ to retain some epithelial structure, but not large enough to carry substantial lamina propria, were ideal to initiate growth (stromal tissue gradually dissociated and died). Matrigel was added until fragments were diluted to approximately 2-10 structures $/ 50 \mu \mathrm{l}$. The minced tissue in Matrigel was aliquotted into LabTek wells at $50 \mu \mathrm{l}$ per well. The media was changed at $3 \mathrm{~h}$ and every $12 \mathrm{~h}$ for the first $48 \mathrm{~h}$, and then subsequently every $24 \mathrm{~h}$.

\section{Passaging and cryopreservation of cultured adenoma tissue}

After approximately 30 days in culture, adenoma structures could be passaged or cryopreserved. The culture was washed once with warm DPBS, followed by incubation for $1 \mathrm{~h}$ at $4{ }^{\circ} \mathrm{C}$ with $1 \mathrm{ml}$ per well of Matrigel Recovery Solution (BD Bioscience) to depolymerize the gelled matrix. The resulting solution was discarded leaving free structures, which were then washed two times in KGMG. To passage for continued expansion, fresh cold Matrigel was added, and the structures were minced and processed as in the original isolation procedure. To freeze, structures were fractured into small pieces with a $1 \mathrm{ml}$ pipet tip (tip end cut back to a diameter permitting aspiration of structure). The pieces were slow frozen with a CoolCell (BioCision, Mill Valley, CA,USA) in $85 \%$ KGMG, 10\% FBS and 5\% dimethyl sulfoxide. To reconstitute cultures, $1 \mathrm{ml}$ vials were rapid thawed and added to $25 \mathrm{ml}$ of warm KGMG-20\% FBS, spun at $100 \times g$ for $2 \mathrm{~min}$ and washed once in KGMG. The thawed structures were suspended in Matrigel, followed by frequent media changes as in the original isolation procedure.

\section{Immunocytochemistry}

\section{Immunofluorescence}

Matrigel was removed from the 3-D-embedded structures with Matrigel Recovery Solution, incubating for $1 \mathrm{~h}$ at $4{ }^{\circ} \mathrm{C}$. 
Subsequently, the structures were prepared for whole-mount immunostaining based on modified methods of Debnath et al. ${ }^{23}$ Briefly, the structures were fixed in $2 \%$ paraformaldehyde for $30 \mathrm{~min}$, DPBS-glycine washed three times, blocked with $10 \%$ goat serum (G6767; Sigma-Aldrich) for $75 \mathrm{~min}$, followed by a secondary block with goat anti-mouse $\mathrm{F}\left(\mathrm{ab}^{\prime}\right)_{2}$ fragment (115-006-006; Jackson ImmunoResearch, West Grove, PA, USA) for 30 min. All blocking, washes and antibody solutions were done with phosphate-buffered solutions containing $0.2 \%$ Triton $\mathrm{X}-100,0.1 \%$ bovine serum albumin and $0.05 \%$ Tween-20. The primary antibodies were incubated overnight at $4{ }^{\circ} \mathrm{C}$ in the secondary block solution, followed by three 20 -min washes at room temperature. The conjugated secondary antibodies were incubated in primary blocking solution for $45 \mathrm{~min}$, followed by three washes. The slides were mounted with Prolong Gold containing DAPI nuclear stain (P36935; Life Technologies Molecular Probes). Primary antibodies for immunofluorescence are listed in Table 3.

\section{Immunofluorescence secondary antibodies}

The antibodies used were Alexa Fluor 488 goat anti-mouse (Molecular Probes A11029); Alexa Fluor 546 goat anti-rabbit (A11035) and anti-rat (A11081); and Alexa Fluor 647 goat anti-mouse (A21236) (Figure 3 only). They were all diluted 1:200, and were manufactured as highly cross-absorbed IgG.

\section{Immunoperoxidase}

Resected pre-isolation adenoma tissue from each donor was formalin fixed and paraffin embedded (Figure 2 inset; Figures 3 and 4). Cultured adenoma were extracted from Matrigel with Matrigel Recovery Solution, DPBS-washed, fixed in 2\% formalin, DPBS-glycine washed three times, held in $70 \%$ ethyl alcohol and then embedded in $20 \mu \mathrm{l}$ HistoGel (American MasterTech, Lodi, CA, USA) before paraffin embedding (Figure 5). Tissue was prepared with heat-induced epitope retrieval (Ventana, Tucson, AZ, USA) and 3,3'-diaminobenzidine peroxidase expression was amplified with either an IView Avidin-Biotin Kit (Ventana) or an Ultraview polymer kit (Ventana). Primary antibodies for immunoperoxidase are listed in Table 3.

\section{Microscopy and Image Analysis \\ Confocal microscopy}

The microscopes used were (1) Leica inverted SP5X confocal microscope with 2-photon FLIM spectral scanning AOBS tunable filters: objective lens $\times 20$, numerical aperture $(\mathrm{NA})=0.7 ; 10 \mu \mathrm{m}$ optical slice (Figure 1c), $4 \mu \mathrm{m}$ (Figures 4 inset, $5 \mathrm{a}$, and $7 \mathrm{e}$ ); objective lens $\times 63$, NA $=1.4$ oil immersion; $1 \mu \mathrm{m}$ (Figure $5 \mathrm{~b}$ ); objective lens $\times 100, \mathrm{NA}=1.4$ oil immersion; $1 \mu \mathrm{m}$ (Figure $7 \mathrm{c},(\times 2.5$ zoom $7 \mathrm{~d}, \mathrm{f}))$, with differential interference contrast (Figures $7 \mathrm{c}-\mathrm{f}$ ); (2) Leica Upright SP5X confocal microscope with 2-photon spectral scanning AOBS tunable filters: objective lens $\times 20$, NA $=0.7$; $10 \mu \mathrm{m}$ (Figure 3); and (3) Zeiss LSM 510: laser excitation wavelengths included $364,488,543 \mathrm{~nm}$ scanned in sequence by the line method; objective lens $\times 20, \mathrm{NA}=0.5 ; 4 \mu \mathrm{m}$ optical slice (Figures 2 and 4c main images). For all ocular lenses, magnification is $10 \times$.

\section{Brightfield Hoffman microscopy}

Olympus IX70, with a DP71 digital camera. Ocular lens $10 \times$. Objective lens $\times 4, \mathrm{NA}=0.13$ (Figure $1 \mathrm{a}) ; \times 10$,

Table 3 Primary antibodies for immunostains

\begin{tabular}{|c|c|c|c|c|}
\hline Antigen & Source & Dilution & Application & Figure \\
\hline \multirow[t]{2}{*}{ Ki67 } & Rabbit polyclonal; ab15580; Abcam, Cambridge, MA, USA & $1: 100$ & IF & $1 c, 3 d, 5 a, 5 b$ \\
\hline & Rabbit monoclonal; ab16667; Abcam & $1: 200$ & IHC-P & $3 a, 5 d$ \\
\hline \multirow[t]{2}{*}{ E-cadherin } & Mouse monoclonal; MAB3199Z; EMD Millipore, Temecula, CA, USA & $1: 100$ & IF & $1 c, 3 d$ \\
\hline & Rabbit monoclonal; ab40772 & $1: 500$ & IHC-P & $3 a, 5 f$ \\
\hline \multirow[t]{3}{*}{ CK20 } & Mouse monoclonal; C9097-29G; US Biological, Swampscott, MA, USA & $1: 100$ & IF & $2 a-d, 4 c, 5 a, 5 b$ \\
\hline & & & IHC-P & $5 c$ \\
\hline & Mouse monoclonal; 320M-16; Cell Marque, Rocklin, CA, USA & $1: 200$ & IHC-P & $2 a$ inset, $4 a$ \\
\hline \multirow[t]{3}{*}{ MUC2 } & Rabbit polyclonal; sc-15334; Santa Cruz Biotechnology, Santa Cruz, CA, USA & $1: 100$ & IF & $2 c, 2 d, 4 c$ \\
\hline & & & IHC-P & $5 e$ \\
\hline & Mouse monoclonal predilute; 760-4388; Ventana Medical Systems, Oro Valley, AZ, USA & None & IHC-P & $2 c$ inset, $4 b$ \\
\hline Bax & Mouse monoclonal; sc-20067; Santa Cruz Biotechnology & $1: 100$ & IHC-P & $6 a-d$ \\
\hline Caspase-3 (cleaved) & Rabbit polyclonal; 9661; Cell Signaling, Danvers, MA, USA & $1: 1000$ & IHC-P & $6 e-h$ \\
\hline Lgr5 & Rat monoclonal; 130-100-876; Miltenyi Biotec GmbH, Bergisch Gladbach, Germany & $1: 1000$ & $\mathrm{IHC}-\mathrm{P}$ and IF & 7 \\
\hline
\end{tabular}

Abbreviations: IF, immunofluorescence; IHC-P, immunohistochemistry-paraffin. 

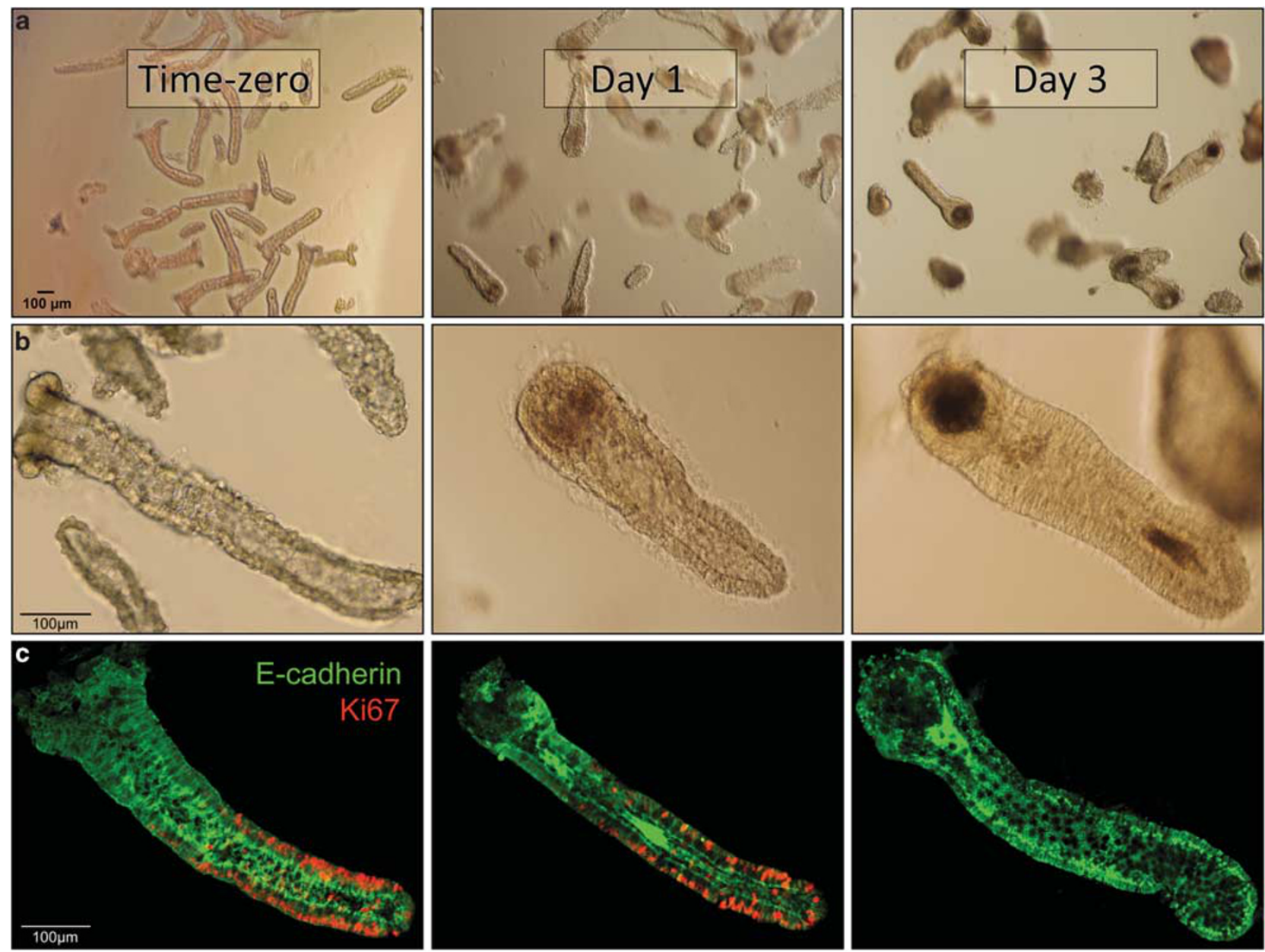

Figure 1 Growth of normal human colonic crypts in culture. Markers of growth and differentiation over time in cultured crypts isolated from histologically normal tissue (resected from two patients, representative of 15 total). Light microscopy images at (a) $40 \times$ and (b) $200 \times(63-y e a r$ female). (c) The proliferation marker Ki67 (orange) and differentiation marker E-cadherin (green) (37-year male).

$\mathrm{NA}=0.25$ (Figure $3 \mathrm{~d}) ; \times 20, \quad \mathrm{NA}=0.4 \quad$ (Figures $1 \mathrm{~b}, \quad 3 \mathrm{~b}$ and 3c).

\section{Examination of immunoperoxidase-stained slides}

The stained tissue slides were scanned/digitized at $\times 20, \times 2$ doubler (Olympus $\mathrm{NA}=0.75$ ) with a ScanScope XT $(0.25 \mu \mathrm{m} /$ pixel; Aperio Technologies, Vista, CA, USA). Images were visualized in Aperio Spectrum Version 11.2.0.780 with Aperio ImageScope Version 11.1.2.760 (Aperio Technologies).

\section{RESULTS}

\section{Isolation, In Vitro Culture and Characterization of Human Colonic Crypts Obtained from Histologically Normal Tissue}

Individual crypts were isolated from histologically normal colon tissue. The average number of crypts obtained per isolation was $10700 \pm 5100$ (range 4400-16200) from $875 \pm 383 \mathrm{mg}$ of mucosal tissue (based on $n=9$ separate isolations). The crypts were embedded in a 3-D matrix and cultured for up to 7 days. Figures $1 \mathrm{a}$ and $\mathrm{b}$ show bright field images of live crypts at time-zero, and then after culture for 1 day and 3 days. The cultured crypts remained similar in appearance to the time-zero structures, with a distinct base and apex. After $24 \mathrm{~h}$ though, the apical opening appeared to close. With extended time in culture, apical cells were shed and the structure gradually shortened. Changes in average crypt length for one representative isolation show time-zero lengths of $500 \pm 47 \mu \mathrm{m}$, with a $16 \pm 22 \%$ reduction in crypt length at day 1 , and a $37 \pm 20 \%$ reduction at day 3 (11-20 crypts measured at each time point). By day 7 , most of the structure had disintegrated.

Figure 1c demonstrates immunofluorescent staining for the proliferation marker Ki67 and the differentiation marker E-cadherin. Ki67 was highly expressed at time-zero and was confined to the proliferative basal half of the crypt. Localized Ki67-positive cells persisted for 1-3 days in culture, but by days 3-5 this marker was absent. In contrast, E-cadherin was 
observed throughout the entire crypt at time-zero and was more highly expressed in cells at the crypt apex. E-cadherin expression did not dissipate over time in culture. In fact, expression increased, especially in the basal area. Two other markers of differentiation were also evaluated: cytokeratin 20 (CK20), an indicator of mature colon epithelial cells and mucin 2 (MUC2), a goblet cell marker. Distinct spatial changes in expression of both markers were observed over time (Figure 2). Specifically, freshly isolated time-zero crypts demonstrated that CK20 expression was confined to the apical surface (Figure 2a). Immunoperoxidase-stained in situ crypts in pre-isolated tissue demonstrate intense staining at the luminal surface (inset). During crypt isolation, the most apical terminally differentiated epithelium was detached from the crypts. By day 3, CK20 expression was seen throughout the entire crypt with strong staining at the crypt base (Figures $2 \mathrm{~b}$ and d). In contrast, MUC2 staining at time-zero was strong in the basal pre-goblet cells, and also extended into the apical
Time-zero
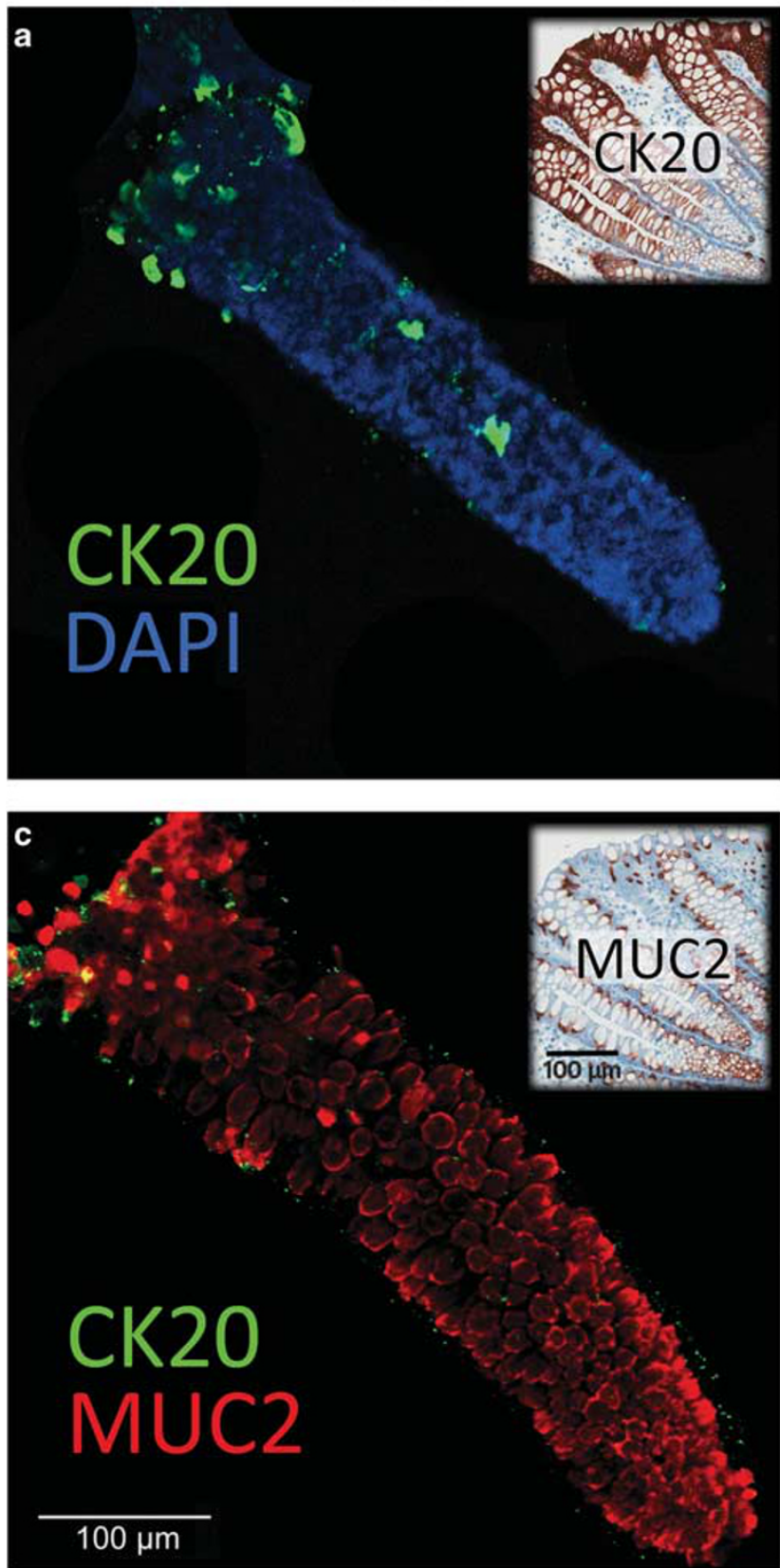

Day 3

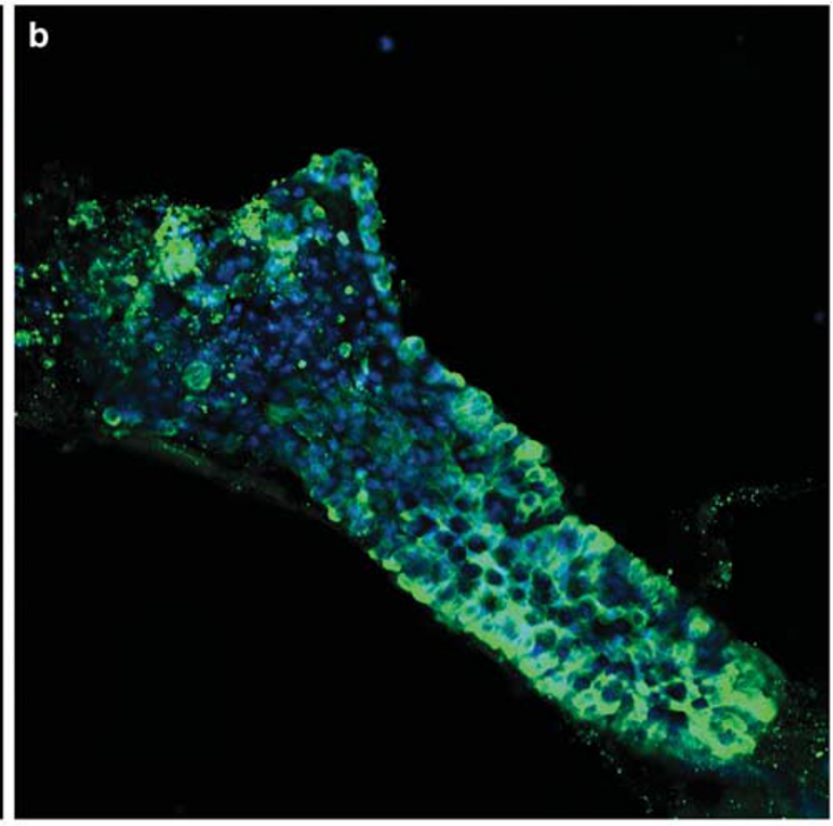

d

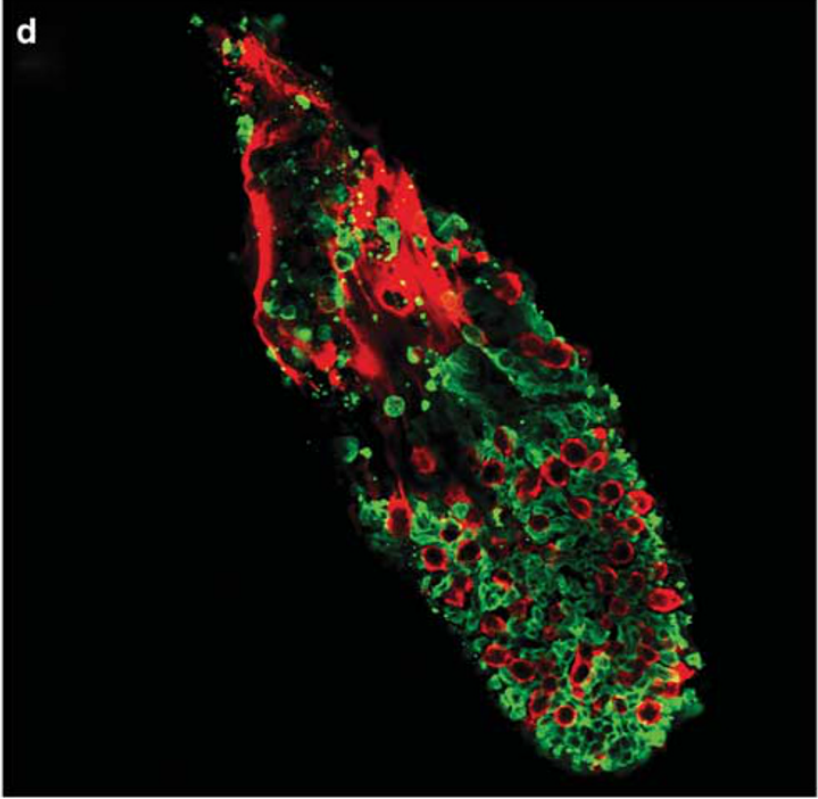

Figure 2 Normal human colonic crypts in culture stained for markers of differentiation, CK20 and MUC2. (a, b) Cytokeratin 20 (green), a marker of mature colon epithelial cells and nuclear DAPI (blue) (64-year male, ascending colon). (c, d) Segregation of CK20 and goblet cell marker MUC2 (red) (41-year female, descending colon). Insets: typical normal colonic mucosa immunoperoxidase-stained for CK20 and MUC2. 
mature goblet cells (as in the in situ crypts; inset; Figure 2c). At day 3, MUC2-positive cells remained but this marker was displaced by abundant CK20 expression (Figure 2d).

\section{Isolation, In Vitro Culture and Characterization of Adenoma-Derived Structures}

Abnormal crypt-like structures were isolated from the adenoma and cultured under the same conditions as crypts from histologically normal tissue. Six of eight donor specimens were successfully cultured. We do not know if the two that were not established simply reflect technical difficulties, or rather intrinsic characteristics of those adenomas. All donors were negative for familial adenomatous polyposis.

Within 2-7 days of seeding, the abnormal crypt-like structures developed well-defined buds and tubules extending outward from a central parent structure (Figures $3 \mathrm{~b}$ and c). In contrast to normal crypts, adenoma-derived structures continued to proliferate, and expanded into macroscopically visible structures. Cultures were maintained through multiple passages (maximum to date, 186 days; Table 2). Moreover, cultured adenoma specimens could be cryopreserved and then successfully returned to culture for continued growth.

In culture, several characteristic features distinguished the adenomatous tissue from histologically normal tissue. The cells in the structures derived from adenomas strongly expressed Ki67 and E-cadherin throughout time in culture (Figures $3 \mathrm{a}$ and d). Ki67 was widespread over the entire structure, but was most intensely expressed at the budding growths (day 15, Figure 3d). E-cadherin was uniformly expressed over the entire epithelium (Figure 3d).

Adenoma cultures from three donors were also stained for CK20 and MUC2 (Figures 4 and 5). In situ (pre-isolation) adenoma tissues showed strong CK20 staining at luminal surfaces with variable, irregular staining deeper into the crypts (Figure 4a). MUC2 expression was also spatially variable, but showed more concentrated expression at the base of the in situ abnormal crypts (Figure 4b). Over time in culture MUC2 and CK20 persisted. Immunofluorescence staining for MUC2 showed characteristic rimming of cells throughout the structures (Figure 4c). CK20 expression was limited to the interior of the structures (Figure 4c, inset).

Immunoperoxidase stained cross-sections of paraffinembedded adenoma structure (day 73) show that MUC2 was seen in goblet cells at varying degrees of cell differentiation, from pre-goblet cells transitioning to mature goblet cells (ie, cells that also expressed CK20), with highest expression in the outer budding regions (Figure 5e). At cross-sectional slices deeper into the cultured adenoma (up to $250 \mu \mathrm{m}$ ), the parent structure was further defined (Figure 5f). The various epithelial cell morphologies, illustrated by E-cadherin staining, suggest differentiated epithelium of the inner parent structure with a reduction of goblet cells (black arrows). The in situ tissue for this donor confirmed a decrease in goblet cells in areas of intense CK20 expression (donor-2;
Figure $4 \mathrm{~b})$. The spatial segregation of the advanced differentiation marker CK20, and the proliferation marker Ki67, is shown in the immunofluorescence stained adenoma at day 24 (Figures $5 \mathrm{a}$ and $\mathrm{b}$ ) and then in the immunoperoxidase stained cross-sections at day 73 (Figures $5 c$ and d). The expression of CK20 was most intensely localized to the central parent structure and its bud junctions (Figures $5 \mathrm{a}$ and $\mathrm{c}$, black arrows), whereas Ki67 expression was strongest at the budding growths (Figures $5 \mathrm{a}$ and $\mathrm{d}$, white arrows).

\section{Markers of Cell Turnover in Cultured Normal Crypts and Adenoma-Derived Structures}

The expression pattern of the pro-apoptotic marker $\mathrm{Bax}^{24}$ (also known as bcl-2-like protein 4) and the apoptotic marker cleaved Caspase-3 were accessed (Table 3, primary antibodies). Bax-positive cells were localized at the apex of the normal crypts at time-zero (Figure 6a), but by day 3 Bax staining was detected in cells further into the base of the crypt (Figure 6b). In contrast, the adenoma tissue (donor-2) showed widespread Bax staining in pre-isolation tissue (Figure 6c) and this pattern persisted in culture through at least day 73 (Figure 6d). In both normal and adenoma, Bax manifested as diffuse and punctate cytoplasmic staining (insets). Punctate cytoplasmic staining of cleaved Caspase-3 was evident at the apex of normal crypts immediately after isolation (Figure 6e) and then by day 3 could be seen further into the basal area of the cultured crypt (Figure 6f inset, white arrow). The adenoma-derived structure had punctate staining throughout the epithelium in pre-isolation tissue (Figure $6 \mathrm{~g}$ ) and this pattern persisted in culture through day 73 (Figure 6h). In addition, cleaved Caspase- 3 stained bodies were seen shed to the interior and exterior of the cultured normal crypts and the adenoma (Figures $6 \mathrm{f}$ and $\mathrm{h}$; inset, black arrows). In a serial section from the same adenoma, the proliferation marker Ki67 (Figure 6d, top inset) is shown localized to budding structures (as demonstrated earlier in this article), where both Bax and cleaved Caspase- 3 were also expressed.

\section{Stem cell Marker Lgr5 Expression in Normal Crypts and Adenoma-Derived Structures}

An antibody to the intestinal stem cell marker $\operatorname{Lgr} 5^{25}$ (leucine-rich repeat-containing G-protein-coupled receptor 5, also known as Gpr49; Table 3, primary antibodies) was used to identify the presence of putative stem cells. The antibody was tested on formalin-fixed paraffin-embedded normal colon mucosa from two patients (Figures $7 \mathrm{a}$ and b). Distinct staining of a few positive cells was present at the base of the crypts. Time-zero isolated crypts were stained by immunofluorescence (Figure 7c) and demonstrated Lgr5 expression in the most basal region. After 1-3 days in culture, Lgr5 was not detected in histologically normal crypts (negative images not shown). In contrast, the adenoma exhibited Lgr5 expression in a few cells in the pre-isolated tissue (Figure 7d) 

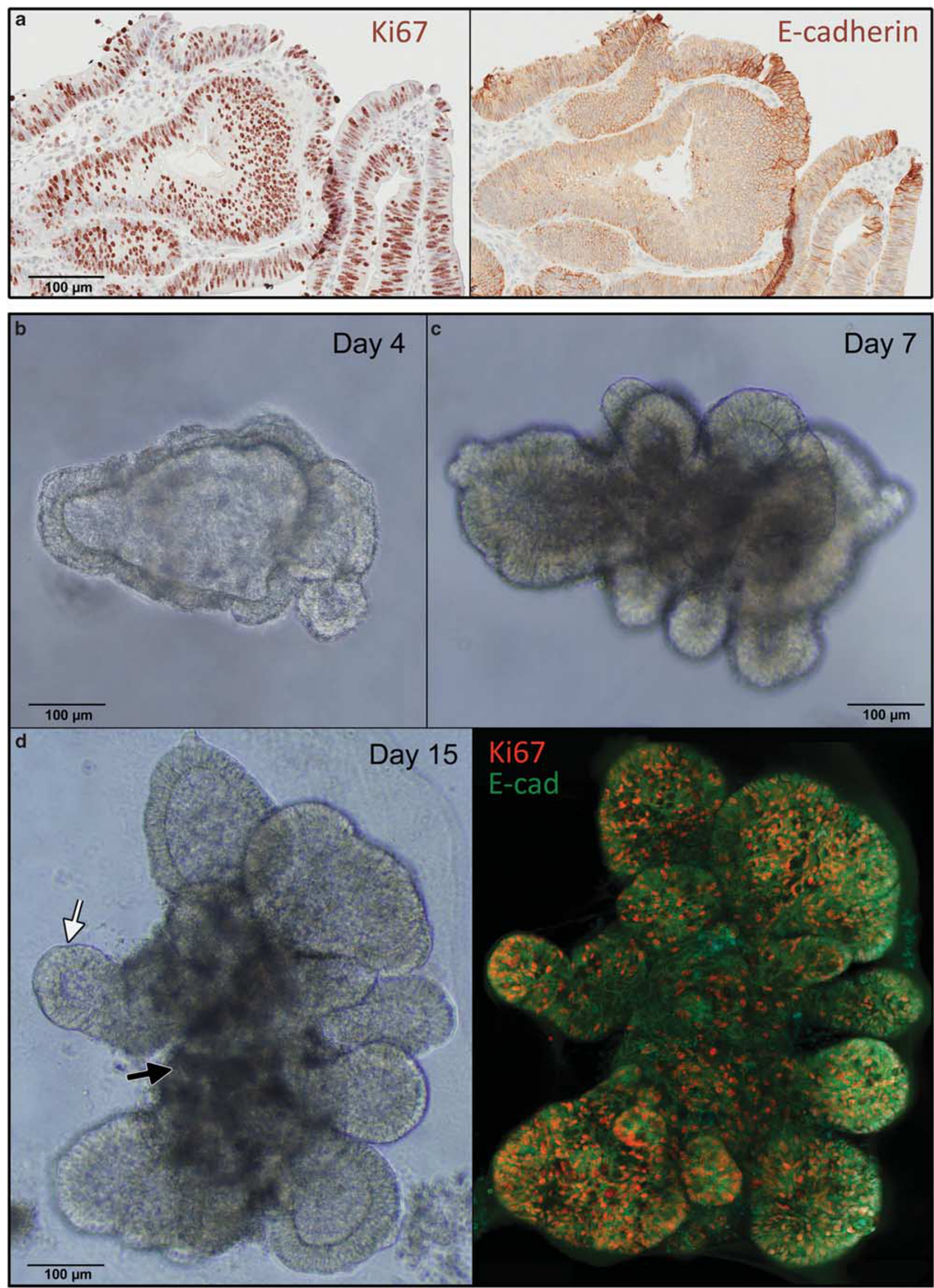
and in the cultured adenoma-derived structures (donor-2) at day 42 (Figure 7e) and day 120 (Figure 7f).

\section{DISCUSSION}

This report describes methods for isolating and maintaining in 3-D culture individual crypts from histologically normal human colon tissue, and crypt-like structures from premalignant adenomas. Large numbers of isolated crypts/ structures can be maintained in culture. Crypts from histologically normal tissue express markers for cell proliferation, differentiation and dissolution in a spatially and temporally distinct manner, over the same 3- to 5-day period as occurs within the normal colonic crypt in vivo (the culture conditions described herein are necessary for the maintenance of normal crypts beyond a few hours). In contrast, the adenoma structures remain viable for extended periods of time (months), and continue to express markers for self-renewal, proliferation, differentiation and apoptosis. Adenomatous
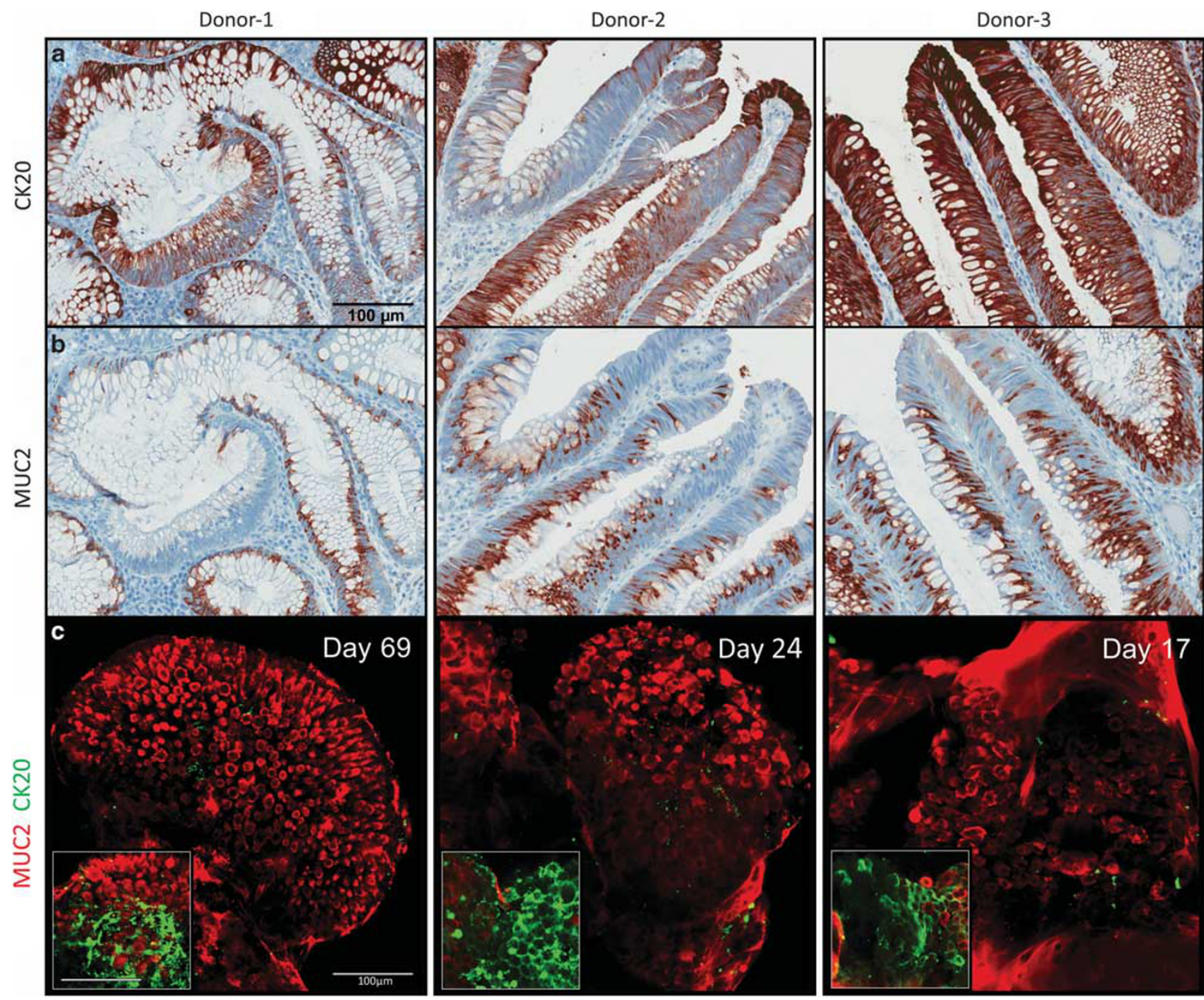

Figure 4 Adenoma-derived structures in culture stained for markers of differentiation, CK20 and MUC2. Resected adenoma (pre-isolation) immunoperoxidase-stained for (a) CK20 and (b) MUC2. (c) Cultured structures predominately expressed MUC2 at exterior proliferative regions. Inset: CK20 (and MUC2 co-staining) is limited to confocal optical slices interior of the largely MUC2-positive exterior. Donor-1: 18-year female. Donor-2: 69-year female. Donor-3: 51-year male. All no evidence of familial adenomatous polyposis.

Figure 3 Human adenoma in culture. (a) Resected adenoma (pre-isolation) immunoperoxidase-stained for Ki67 and E-cadherin. (b-d) Cultured adenoma light microscopy images show structural changes over time; budding and tubular formation (white arrow) from the central parent structure (black arrow). (d) At day 15, the adenoma is stained for the proliferation marker Ki67 (orange) and the differentiation marker E-cadherin (green); nuclear DAPI (blue; whitish co-expression with red and green stains). The tissue originated from an 18-year female (donor-1) with a large adenoma and no evidence of familial adenomatous polyposis. 

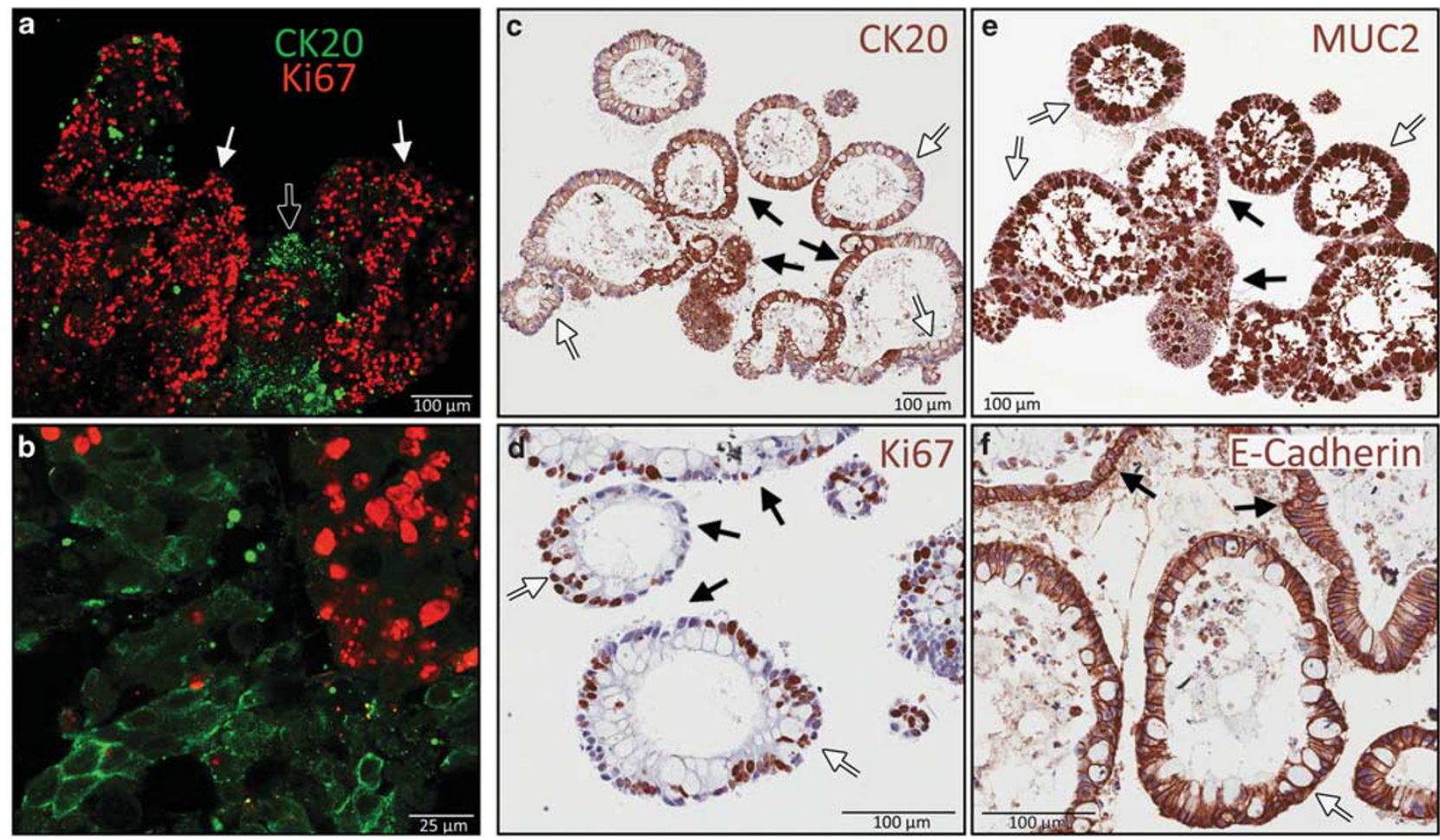

Figure 5 Growth of adenoma in culture: segregation of markers for growth and differentiation. (a-f) Proliferating bud regions (white arrows) and parent structure with connecting bud stem regions (black arrows). (a, b) Confocal immunofluorescence at day 24 (donor-2) showing segregation of Ki67 to proliferating outer regions and CK20 to parent structure. (b) Representative high magnification of panel a immunofluorescence marker expression. (c-f) Immunoperoxidase stained cross-section of one structure with multiple budding growths (third passage; day 73). (c) Localization of CK20 to inner epithelium adjoining parent structure. (d) High magnification of buds with proliferating Ki67-positive outer regions. (e) MUC2-positive pre-goblet (overlapping proliferative regions in panel c) and mature goblet cells (overlapping CK20-positive regions in panel c). (f) Cross-sectional cut further into paraffin-embedded adenoma showing more parent structure. E-cadherin uniformly expressed throughout epithelium.

crypt structures can be expanded, cryopreserved and then reestablished in culture. Equally important, maintenance of both the normal and abnormal crypts can be accomplished with a readily available, 'simple' growth medium.

In the 3-D crypt culture model described here, there is the potential to examine a variety of biochemical and molecular markers under basal conditions, but more importantly to directly assess the effects of various interventions on their expression. A single crypt isolation from a small portion of resected normal tissue ( $1 \mathrm{~g}$ of mucosal tissue), yields large numbers of crypts, with an average of $10700 \pm 5100$ crypts per isolation. At 50 crypts per well, 200 separate 3-D experimental units could be prepared from an average yield. Similarly, isolations expanded (and cryopreserved) from a single $5 \mathrm{mg}$ biopsy of adenomatous tissue allow for numerous experimental units.

In this study, we compared the in vitro growth characteristics and biomarker expression patterns between histologically normal crypts and structures derived from adenomas. Not surprisingly, expression of the proliferation marker Ki67 paralleled growth characteristics in both normal and adenomatous crypts. In normal crypts, this marker was strongly expressed in the basal half of the crypt at isolation, but decreased to an undetectable level over a 3 - 5-day period. In contrast, continued expression of Ki67 was seen in the adenomatous crypts in culture and was most intense in budding structures. We infer that this in vitro component likely corresponds to the proliferating region of the adenoma in vivo.

Expression patterns for three differentiation-associated markers were examined in parallel with Ki67. These included E-cadherin, MUC2 and CK20. E-cadherin is a calciumdependent transmembrane protein that maintains epithelial cell cohesion and has a role in growth control. ${ }^{26}$ Loss of E-cadherin has been linked to the progression of colon carcinogenesis. CK20 is expressed in mature normal intestinal epithelial cells (enterocytes, goblet cells and endocrine cells), and most colorectal cancers. ${ }^{27}$ MUC2 is a goblet cell marker seen in various degrees of differentiation from basal pre-goblet cells to mature goblet cells. ${ }^{28,29}$ Both CK20 and MUC2 are used diagnostically in colon cancer to help determine if a carcinoma has intestinal differentiation. CK20 (in the absence of CK7), is often helpful to establish the colon (and other more rare intestinal carcinomas) as the tissue of origin when observed in distant metastases. ${ }^{27,30,31}$ High expression of MUC2 in the colon is more commonly 

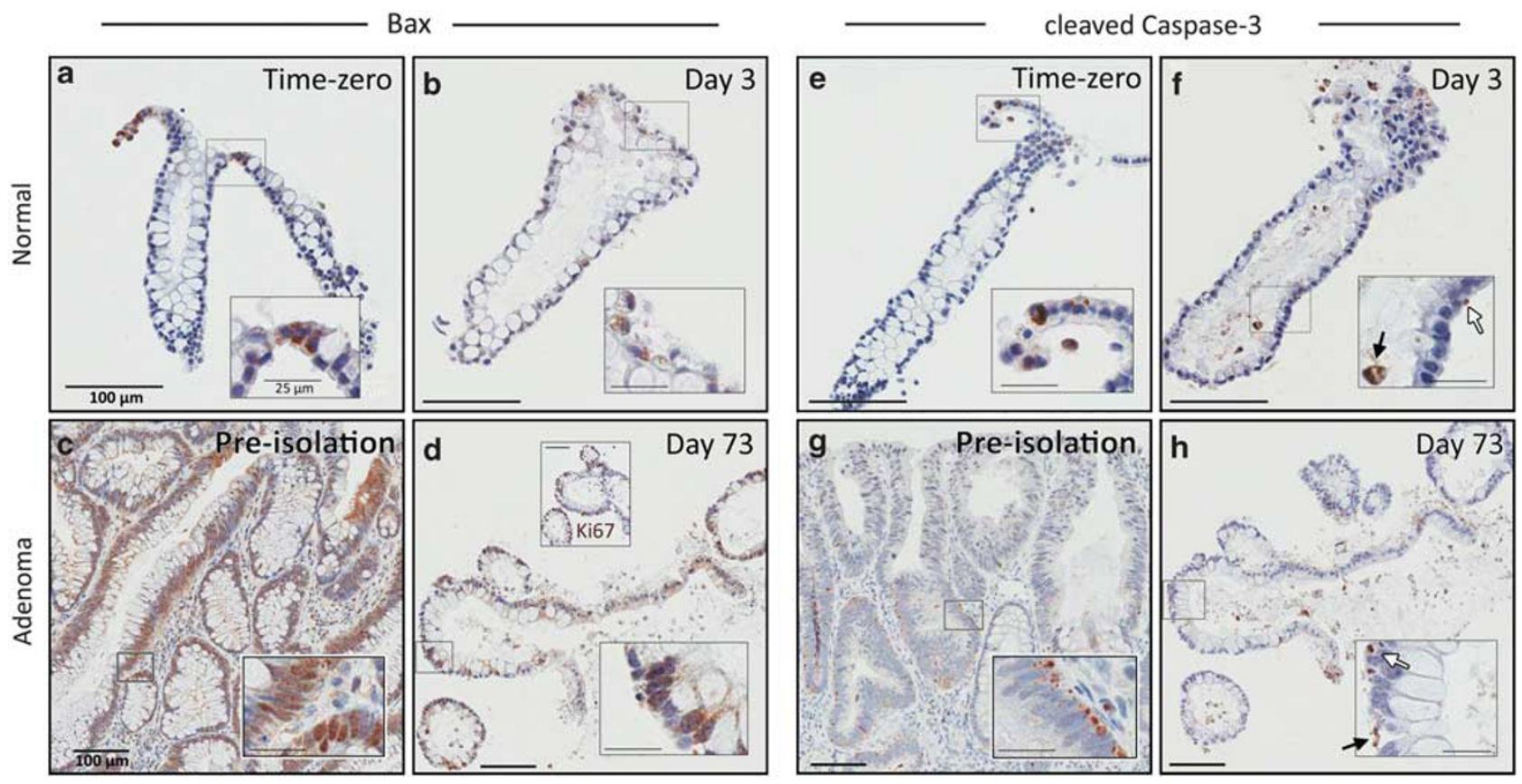

Figure 6 Expression of pro-apoptotic marker Bax and apoptotic marker, cleaved Caspase-3 in cultured normal colonic crypts and adenoma. Immunoperoxidase-stained paraffin-embedded normal crypts before/after 3 days in culture and adenoma (donor-2) before/after 73 days in culture (main image scale bar $100 \mu \mathrm{m}$ ). Insets: regions enlarged to demonstrate marker localization (scale bars $25 \mu \mathrm{m}$ ). (a-d) Bax as punctate and diffuse cytoplasmic staining, and (e-h) cleaved Caspase-3 as punctate cytoplasmic staining (white arrows) and stained shed bodies (black arrows). (d, top inset) Ki67 expression of a parallel serial section (scale bar $100 \mu \mathrm{m}$ ).

associated with adenomas characterized with mild dysplasia, as compared with adenomas of high grade dysplasia. ${ }^{32}$

Significant differences were observed among the three differentiation markers, and these differences led to distinct expression profiles in normal and adenoma tissue. In normal crypts, MUC2-expressing cells were predominant in the basal half of the crypt at time-zero. Normal crypts in culture showed a transient increase in MUC2 as the crypt progressed through differentiation, but eventually staining declined. In contrast, E-cadherin and CK20 increased over the same time period. The increase in expression of CK20 was especially pronounced in the normal crypts; from minimal apical expression at time-zero to strong staining throughout the crypt by day 3. By day 3, the remaining MUC2-positive cells were surrounded by CK20 expressors. The reduced MUC2 staining at day 3 (and beyond), coupled with increased CK20, may simply reflect the commitment of the goblet cells to terminal differentiation and death. ${ }^{27}$ Alternatively, increased CK20 expression might also reflect the emergence in culture of the enterocyte lineage. As this possibility was not assessed here, the resolution awaits further study.

In adenomas, the differentiation markers E-cadherin and MUC2 were widely observed throughout the tissue over the entire culture period. MUC2 expression was strong in the proliferating regions of the cultured adenomas, specifically in the buds expanding from the parent central structure. As expected, these regions, which also had high Ki67 expression, had limited CK20 levels. CK20 was detected in adenoma cultures as late as day 73 (latest time-point analyzed), but was localized to areas of advanced differentiation in the parent structure and at the adjoining stems of budding structures. This was evident in the confocal fluorescence images of the 3-D cultures and confirmed in the immunohistological sections.

The progression to final cellular dissolution was assessed in the crypt culture model with the pro-apoptotic marker Bax, and the apoptotic marker cleaved Caspase-3. The isolated normal crypts in culture exhibited the expected apoptotic marker distribution; at the initiation of culture both markers were expressed at the apex, with increased staining into the crypt over time. Although Bax is known to be constitutively present in normal healthy cells (expressed as diffuse cytoplasmic staining), ${ }^{24}$ the punctate staining here was localized to the apex, so was more predictive of cleaved Caspase-3 staining. In contrast to time-zero normal crypts, the preisolation adenoma showed extensive staining of Bax (diffuse and punctate) and cleaved Caspase-3 (punctate). The cultured adenoma followed this widespread expression pattern of Bax and cleaved Caspase-3. These adenomaderived structures further showed that the apoptotic markers were not segregated to the terminally differentiated regions (parent structure), but also co-existed in areas of proliferation (Ki67-positive; budding regions). Cell turnover within the normal colonic mucosa, and the timing and role of apoptosis as a mechanism, is currently not understood. ${ }^{33}$ In flat normal mucosa, apoptotic events may regulate epithelial cell shedding into the lumen; 

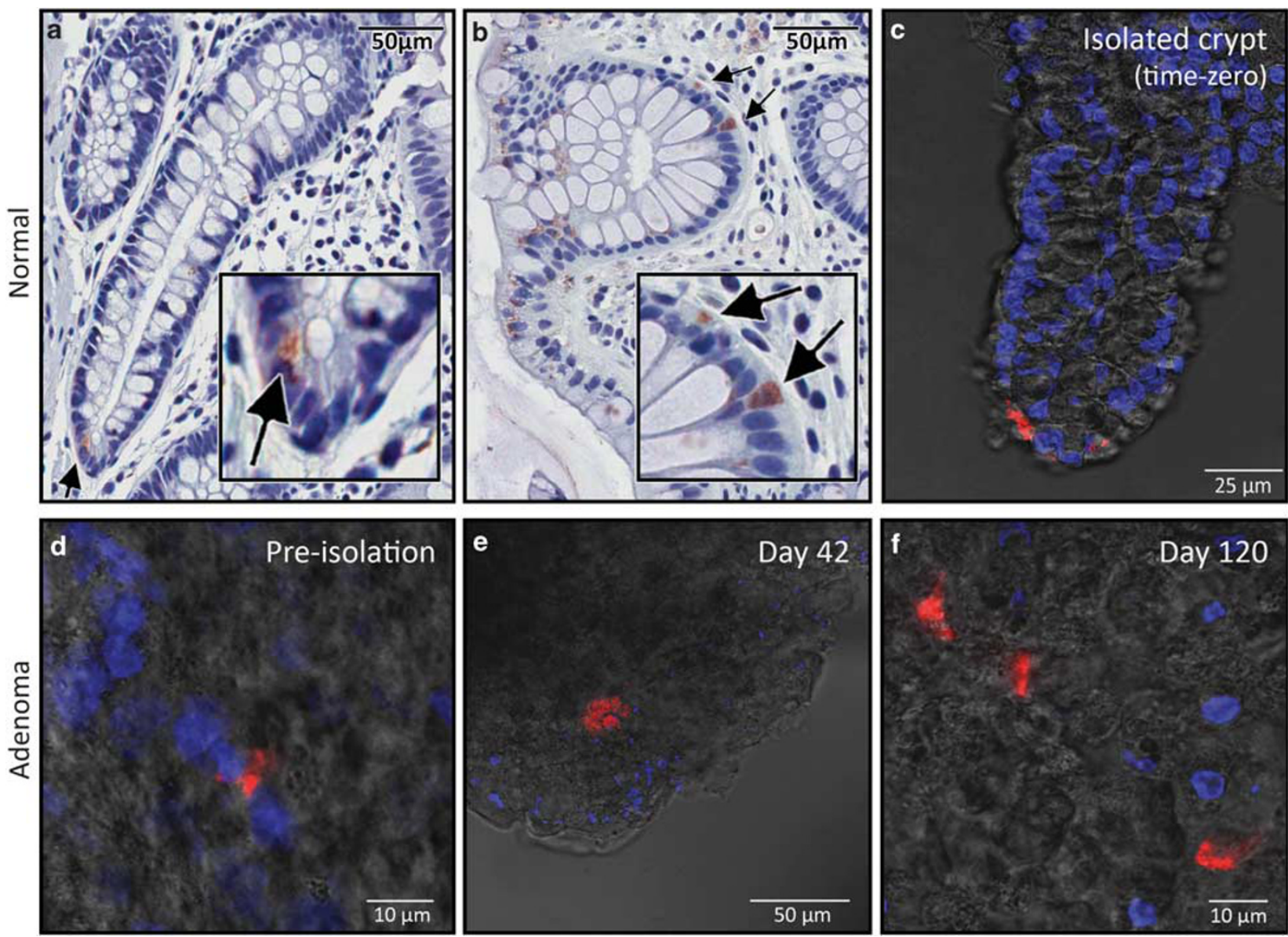

Figure 7 Expression of intestinal stem cell marker Lgr5 in normal colonic mucosa and cultured adenoma. (a, b) Examples of Lgr5 immunoperoxidasestained normal colonic mucosa from two subjects, demonstrating localized specificity to a few basal cells (inset $2 \times$ image). (c-f) Confocal immunofluorescence with differential interference contrast; Lgr5 (red) and nuclear DAPI (blue). (c) Time-zero isolated normal crypt. (d) Pre-isolation adenoma. (e) Cultured adenoma (donor-2) at day 42 and (f) day 120.

alternatively, cell detachment itself may cause anchoragedependent apoptosis (anoikis); ${ }^{34}$ or both processes may be involved in cellular turnover. The apoptosis profile of cultured crypts demonstrated here does not define the sequence of events, which underlie the shedding of supposed apoptotic cells. This being said, the adenoma staining for apoptosis and proliferation suggests that the expansion of the structure does not reflect an absolute reduction in cell turnover, but instead a kinetic imbalance between the two processes.

The sustained expansion of the adenoma structure may indeed be due in part to unregulated self-renewal. In this study, our goal was not to optimize culture conditions to support self-renewal of the stem cell compartment (addition of Wnt3a; Noggin; R-spondin; ROCK, ALK and p38 MAPK inhibitors). ${ }^{16,17}$ Instead the progression of colon epithelial cells in crypts was examined independent of this process. Crypts from histologically normal tissue underwent progression from growth to differentiation to dissolution within a 3-5-day period, mimicking the cell cycle changes in vivo. Although time-zero freshly isolated crypts expressed the stem cell marker Lgr5, normal crypts in culture did not indicate the presence of Lgr5. This staining was indeed a rare event even in intact mucosa and time-zero crypts, so the exact timing of its disappearance under these culture conditions was not determined. The same conditions were used for the maintenance of the adenoma crypts. Unlike the normal crypts though, these abnormal structures continued to express the Lgr5 stem cell marker and demonstrated a positive cell cycle balance. We believe this system for normal and abnormal crypt culture will provide a platform to compare processes that drive the colonic crypt physiology/ pathophysiology.

Our future studies will assess responses of the histologically normal crypts and adenoma-derived structures to pharmacologic or nutriceutical interventions designed to reverse or delay carcinogenesis. For example, increased calcium concentrations that would mimic levels achieved in human chemoprevention trials ${ }^{35-37}$ (ie, 2.5-7.0 mM) can be tested in this model with targeted and potentially individualized concentrations defined. In addition to evaluating agents for potential chemopreventive activity, the 
primary culture of human colon crypts should help us elucidate underlying molecular mechanisms of chemoprevention, and help determine the stage of tumor development at which potential chemopreventative agents may be effective.

In summary, these studies provide a means to readily obtain large numbers of human colonic crypts from normal and adenomatous mucosa and to maintain the crypts in culture under conditions in which the differences between the histologically normal crypts and the adenomatous crypts are preserved. This model should be a valuable tool in studying the biology and progression of colon neoplasia initiation and development, as well as a platform to assess potential cancer risk reductive agents in a preclinical human system.

\section{ACKNOWLEDGMENTS}

This study was supported by 11-0577 Association for International Cancer Research, St Andrews, Fife, Scotland; NIH R21 CA140760-02; NIH 5R01 GM068848; and NIH P50 CA130810 (GI SPORE, DE Brenner, PI), the Kutsche Family Endowed Chair in the Department of Internal Medicine and the Geriatrics Research Education and Clinical Center at the Ann Arbor VA Medical Center. We thank Olaf Thorsten Hardt, PhD and David Agorku of Miltenyi Biotec $\mathrm{GmbH}$ for providing their novel Lgr5 antibody as a gift; Shibani Mukherjee, PhD of the Fred Hutchinson Cancer Research Center, for her assistance with immunofluorescence of matrigel-embedded structures; Caitlin Breakey, clinical coordinator, the University of Michigan Hospitals, for her assistance in obtaining adenoma biopsies; Deborah Postiff and Jackline Barikdar of the Tissue Procurement Core Laboratory, Comprehensive Cancer Center, as the source of normal tissue specimens (P30 CA46592); Bruce Donohoe and Sasha Meshinchi of the Microscopy and Image Analysis Laboratory, Biomedical and Research Core Facilities (C941037); Paula Arrowsmith and Wendy Rosebury-Smith of Histology Services, Pathology Cores for Animal Research, Unit for Laboratory Animal Medicine; and Ron Craig, PhD of the Histomorphometry Core, Department of Pathology, for his ScanScope service and assistance.

\section{DISCLOSURE/CONFLICT OF INTEREST}

The authors declare no conflict of interest.

1. Whitfield JF. Calcium, calcium-sensing receptor and colon cancer. Cancer Lett 2009;275:9-16.

2. Creamer B, Shorter RG, Bamforth J. The turnover and shedding of epithelial cells. I. The turnover in the gastro-intestinal tract. Gut 1961;2:110-118.

3. Yuasa Y. Control of gut differentiation and intestinal-type gastric carcinogenesis. Nat Rev Cancer 2003;3:592-600.

4. Takayama T, Ohi M, Hayashi T, et al. Analysis of K-ras, APC, and betacatenin in aberrant crypt foci in sporadic adenoma, cancer, and familial adenomatous polyposis. Gastroenterology 2001;121:599-611.

5. Burgart $\sqcup$. Colorectal polyps and other precursor lesions. Need for an expanded view. Gastroenterol Clin North Am 2002;31:959-970.

6. Taketo MM, Edelmann W. Mouse models of colon cancer. Gastroenterology 2009;136:780-798.

7. Gouyer V, Fontaine D, Dumont $P$, et al. Autocrine induction of invasion and metastasis by tumor-associated trypsin inhibitor in human colon cancer cells. Oncogene 2008;27:4024-4033.

8. Knosel $T$, Emde V, Schluns $K$, et al. Cytokeratin profiles identify diagnostic signatures in colorectal cancer using multiplex analysis of tissue microarrays. Cell Oncol 2006;28:167-175.

9. Kheirelseid EA, Miller N, Chang KH, et al. Clinical applications of gene expression in colorectal cancer. J Gastrointest Oncol 2013;4:144-157.

10. Trier JS. Organ-culture methods in the study of gastrointestinalmucosal function and development. N Engl J Med 1976;295:150-155.

11. Autrup H. Explant culture of human colon. Methods Cell Biol 1980;21B:385-401.
12. Dame MK, Bhagavathula N, Mankey C, et al. Human colon tissue in organ culture: preservation of normal and neoplastic characteristics. In Vitro Cell Dev Biol Anim 2010;46:114-122.

13. Whitehead RH, Brown A, Bhathal PS. A method for the isolation and culture of human colonic crypts in collagen gels. In Vitro Cell Dev Biol 1987;23:436-442.

14. Grossmann J, Walther $\mathrm{K}$, Artinger $\mathrm{M}$, et al. Progress on isolation and short-term ex-vivo culture of highly purified non-apoptotic human intestinal epithelial cells (IEC). Eur J Cell Biol 2003;82:262-270.

15. Kalabis J, Patterson MJ, Enders GH, et al. Stimulation of human colonic epithelial cells by leukemia inhibitory factor is dependent on collagenembedded fibroblasts in organotypic culture. FASEB J 2003;17: $1115-1117$.

16. Jung $\mathrm{P}$, Sato $\mathrm{T}$, Merlos-Suarez $\mathrm{A}$, et al. Isolation and in vitro expansion of human colonic stem cells. Nat Med 2011;17:1225-1227.

17. Sato $T$, Stange $D E$, Ferrante $M$, et al. Long-term expansion of epithelial organoids from human colon, adenoma, adenocarcinoma, and Barrett's epithelium. Gastroenterology 2011;141:1762-1772.

18. Vainer B, Sorensen S, Seidelin J, et al. Expression of ICAM-1 in colon epithelial cells: an ultrastructural study performed on in vivo and in vitro models. Virchows Arch 2003;443:774-781.

19. Li XM, Patel BB, Blagoi EL, et al. Analyzing alkaline proteins in human colon crypt proteome. J Proteome Res 2004;3:821-833.

20. Kinugasa T, Kuroki M, Yamanaka $T$, et al. Non-proteolytic release of carcinoembryonic antigen from normal human colonic epithelial cells cultured in collagen gel. Int J Cancer 1994;58:102-107.

21. O'Keane JC, Kupchik HZ, Schroy PC, et al. A three-dimensional system for long-term culture of human colorectal adenomas. Am J Pathol 1990;137:1539-1547.

22. Dame MK, Varani J. Human colon tissue in organ culture. In: Davies J (ed). Replacing Animal Models: A Practical Guide to Creating and Using CultureBased Biomimetic Alternatives. John Wiley: Chichester, 2012, pp 69-80.

23. Debnath J, Muthuswamy SK, Brugge JS. Morphogenesis and oncogenesis of MCF-10A mammary epithelial acini grown in three-dimensional basement membrane cultures. Methods 2003;30:256-268.

24. Youle RJ, Strasser A. The BCL-2 protein family: opposing activities that mediate cell death. Nat Rev Mol Cell Biol 2008;9:47-59.

25. Barker $\mathrm{N}$, van Es JH, Kuipers J, et al. Identification of stem cells in small intestine and colon by marker gene Lgr5. Nature 2007;449:1003-1007.

26. Pignatelli M. E-cadherin: a biological marker of tumour differentiation. J Pathol 1993;171:81-82.

27. Uhlen $M$, Oksvold $P$, Fagerberg $L$, et al. Towards a knowledge-based Human Protein Atlas. Nat Biotechnol 2010;28:1248-1250.

28. Yonezawa S, Yamada N, Yokoyama S, et al. MUC2 (mucin 2, oligomeric mucus/gel-forming). Atlas Genet Cytogenet Oncol Haematol 2010;14: 827-833.

29. Katz JP, Perreault N, Goldstein BG, et al. The zinc-finger transcription factor Klf4 is required for terminal differentiation of goblet cells in the colon. Development 2002;129:2619-2628.

30. Moll R, Schiller DL, Franke WW. Identification of protein IT of the intestinal cytoskeleton as a novel type I cytokeratin with unusual properties and expression patterns. J Cell Biol 1990;111:567-580.

31. Zhou Q, Cadrin M, Herrmann $H$, et al. Keratin 20 serine 13 phosphorylation is a stress and intestinal goblet cell marker. J Biol Chem 2006;281:16453-16461.

32. Li A, Goto M, Horinouchi $M$, et al. Expression of MUC1 and MUC2 mucins and relationship with cell proliferative activity in human colorectal neoplasia. Pathol Int 2001;51:853-860.

33. Gunther C, Neumann H, Neurath MF, et al. Apoptosis, necrosis and necroptosis: cell death regulation in the intestinal epithelium. Gut 2013;62:1062-1071.

34. Bullen TF, Forrest S, Campbell F, et al. Characterization of epithelial cell shedding from human small intestine. Lab Invest 2006;86:1052-1063.

35. Grau MV, Baron JA, Sandler RS, et al. Prolonged effect of calcium supplementation on risk of colorectal adenomas in a randomized trial. J Natl Cancer Inst 2007;99:129-136.

36. Baron JA, Beach M, Mandel JS, et al. Calcium supplements for the prevention of colorectal adenomas. Calcium Polyp Prevention Study Group. N Engl J Med 1999;340:101-107.

37. Ahearn TU, McCullough ML, Flanders WD, et al. A randomized clinical trial of the effects of supplemental calcium and vitamin D3 on markers of their metabolism in normal mucosa of colorectal adenoma patients. Cancer Res 2011;71:413-423. 